\title{
CHRONIC REGIONAL ENTERITIS IN CHILDHOOD
}

BY

\author{
T. G. MADDISON and I. HYDE \\ From the Children's Hospital, Birmingham
}

(RECEIVED FOR PUBLICATION APRIL 13, 1955)

Regional enteritis was first described by Crohn, Ginzburg and Oppenheimer in 1932. Although many adult cases of this condition have been described, there are few reports of chronic regional enteritis in childhood (Meade, 1941; Bockus, 1945; Koop, Perlingiero and Weiss, 1947; Oleson, 1952). Crohn (1949) reported six (2.7\%) under 10 years of age out of a total series of 222 cases; Shapiro, Ravdin and Johnston (1939), in a review of the literature, gave an incidence of $4.7 \%$, but did not indicate whether this figure included both acute and chronic cases.

The aetiology of chronic regional enteritis is still unknown. The pathological picture is one of chronic inflammation with healing by fibrosis which involves the whole intestinal wall and regional lymph nodes.

The purpose of the present paper is to describe two cases, one of which has been treated with corticotropin (A.C.T.H.).

\section{Case Reports}

Case 1. A boy, aged 10 years, was admitted to the Birmingham Children's Hospital on October 19, 1954. He had been well until 12 months before admission when he developed persistent diarrhoea; at times it became more severe but he usually had three or four brown, liquid stools daily containing mucus but no blood. He gradually lost weight and became lethargic and pale. It was noticed that he perspired at night and occasionally appeared feverish. There was no history of vomiting or abdominal distension.

On admission he was pale, underweight and looked ill. General examination revealed no other abnormality.

Peripheral blood examination showed a haemoglobin of $9 \cdot 7$ g. per $100 \mathrm{ml}$., red blood cells $4,200,000$ per c.mm., white blood cells 12,600 per c.mm. with $78 \%$ polymorphs. The Mantoux (1:1,000 and 1:100 dilutions of old tuberculin) and Wassermann reactions were negative. Repeated stool examinations revealed no abnormality on microscopy or culture. The occult blood test was negative.

A radiological examination was made by Dr. $R$. Astley. A barium enema showed a narrowing of the proximal ascending colon and caecum. Retrograde flow into the ileum revealed a similar stenosis in the terminal few inches (Fig. 1). The narrowing ended abruptly and

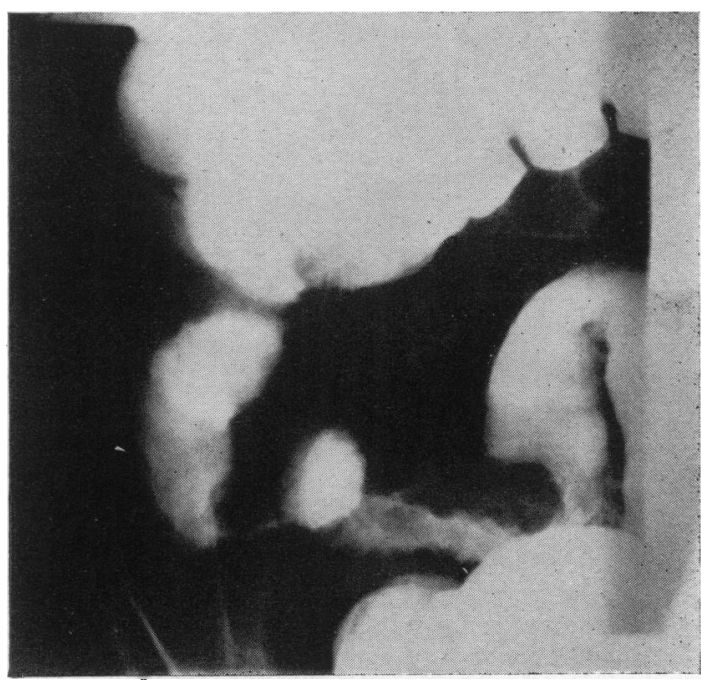

FIG. 1.-Barium enema showing terminal ileum, caecum and proximal ascending colon.

above this level the small intestine was slightly dilated. In the narrow area the outline of the bowel was rather shaggy and showed a close, shallow scolloping. A follow-through examination two days later confirmed these findings; there was very little obstruction to the passage of the barium.

During the first 17 days in hospital, despite rest in bed and a high-protein, low-residue diet with added vitamins, he continued to lose weight and the diarrhoea persisted.

A.C.T.H. was then begun, using the gel preparation by intramuscular injection once daily. The initial dosage was 40 units (approximately 1 unit per $1 \mathrm{lb}$. body weight) for three weeks with gradual reduction of dosage thereafter; over 80 days he received 2,145 units of A.C.T.H. Ferrous gluconate and potassium chloride were also given orally. His appetite and general well-being improved and there was a gradual gain in weight (Fig. 3). Eighteen days after beginning A.C.T.H. he passed a normal formed stool. The stools have remained normal, usually with one bowel motion daily or every second day. The haemoglobin concentration slowly rose to $14 \mathrm{~g}$. per 
$100 \mathrm{ml}$. The A.C.T.H. was discontinued when he developed a paronychia which responded to a five-day course of aureomycin.

A barium enema five weeks after stopping A.C.T.H. showed that there was still narrowing of the caecum and terminal ileum, but that the bowel now had a well defined although irregular outline, suggesting healing (Fig. 2).

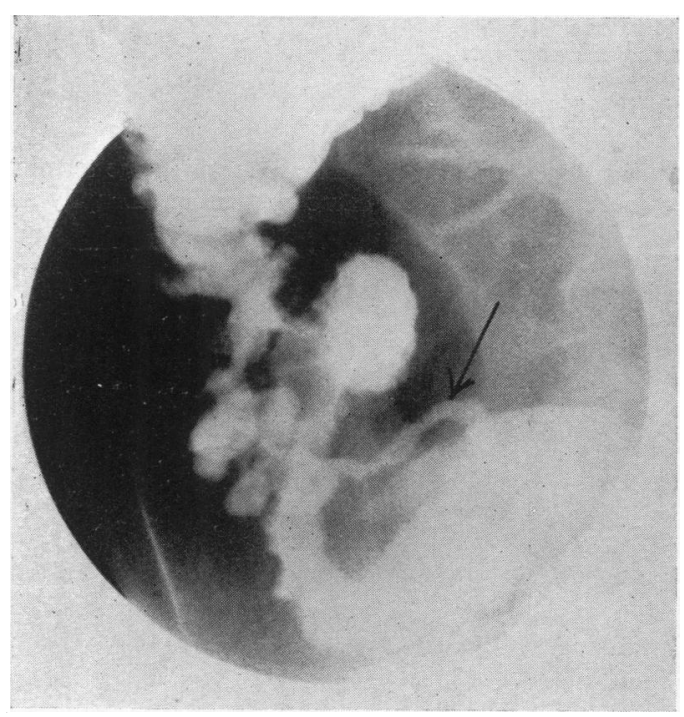

FIG. 2.-Barium enema five weeks after stopping A.C.T.H. Appendix also demonstrated.

In places there were diverticula-like projections. At this examination the appendix, not previously demonstrated, was also seen to have an irregular but sharply outlined lumen.

Case 2. A boy, aged 12 years, was admitted to the Birmingham Children's Hospital on September 4, 1951. During the preceding nine months he had had recurrent attacks of vomiting which occurred on average two or three times a week, but were not associated with abdominal pain. He had progressively lost weight, lacked energy and become pale. The stools were normal.

On admission he was a pale, thin boy who looked ill; there was a tender palpable mass occupying most of the right iliac fossa.

Peripheral blood examination showed a haemoglobin of $8 \cdot 8 \mathrm{~g}$. per $100 \mathrm{ml}$., red blood cells $4,000,000$ per c.mm., white blood cells 6,500 per c.mm. with $70 \%$ polymorphs. The Mantoux reaction was negative.

A barium enema demonstrated that the lumen of the caecum and ascending colon was narrowed to a small, irregular channel beyond which the contrast medium would not flow. A follow-through examination showed that the terminal ileum was also involved, with considerable dilatation of the small intestine more proximally, but no delay in transit. The narrowed bowel and the dilatation above it could be identified by gas shadows in direct radiographs of the abdomen.

Laparotomy was performed by Mr. R. K. Debenham on September 22, 1951. The palpable mass consisted of thickened, reddened, oedematous terminal ileum, caecum, a portion of the ascending colon and enlarged mesenteric lymph nodes. The distal ileum was dilated for several feet proximal to the mass. The terminal ileum (14 in.), caecum and ascending colon ( 2 in.) were resected and an end-to-side anastomosis performed; post-operative convalescence was uneventful.

A pathological examination was made by Dr. H. S. Baar.

The wall of the ileum showed a continuous thickening in a caudal direction, the proximal end having a thickness of $1 \mathrm{~mm}$. and the distal end $6 \mathrm{~mm}$. The wall of the caecum was also thickened. There were submucous haemorrhages in the distal part of the ileum along the mucosal folds. The appendix was embedded in fibrous tissue and its wall was extremely thickened up to $6 \mathrm{~mm}$. At the ileo-caecal junction there was a plum-sized mass which consisted of enlarged lymph nodes and fibrous tissue. Most of this mass was, on the cut surface, white with pinkish-grey and ochre yellow areas.

The mass consisted of an extremely oedematous granulation tissue within which plain muscle fibres were enclosed. The appearance of the granulation tissue varied; some areas showed mainly capillaries and fibroblasts, others showed many eosinophil leucocytes, while in some areas there were dense, diffuse aggregations of reticulum cells or of plasma cells. In such areas giant cells of the Langhans type were seen, but there were only occasional circumscribed granulomata with giant cells. The appendix showed complete ulceration of its mucosa and the lumen was surrounded by granulation tissue. The central part of the latter was very cellular with reticulum cells, plasma cells and giant cells; the periphery consisted of oedematous, less cellular, granulation tissue with fibroblasts and eosinophil leucocytes.

The boy has remained very well since the operation and has gained weight normally, but does have an occasional loose stool.

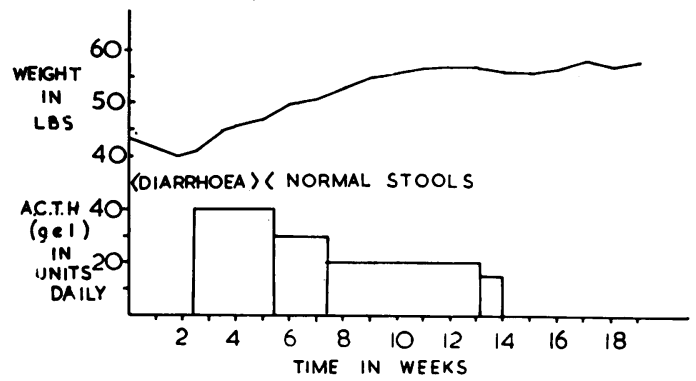

Fig. 3.-Progress in hospital.

\section{Discussion}

There have been many reported cases of acute regional enteritis in children (Erb and Farmer, 1935; Probstein and Gruenfeld, 1936; Mailer, 1938; 
Harris, 1940; Meade, 1941; Ebrill, 1945; Storrs and Hoekelman, 1953). These cases have usually presented with symptoms and signs suggestive of an acute abdominal emergency, e.g. appendicitis, and the diagnosis has been made at laparotomy. Recovery in such is often complete and Storrs and Hoekelman, who reported eight cases with a long follow-up, believe that it is a specific entity unrelated to chronic regional enteritis. Other authors, however, suggest that some cases do progress to the chronic condition (Harris, 1940; Meade, 1941; Crohn, 1949).

Chronic regional enteritis, whilst a rarity in childhood, must be considered in the differential diagnosis of any subacute or chronic abdominal disorder. Our first case presented with chronic and persistent diarrhoea suggestive of ulcerative colitis and on abdominal examination there was no demonstrable pain, tenderness or rigidity and no tumour mass palpable. Bacteriological examination was negative for pathogenic organisms. The diagnosis was established by radiological examination. In the second case the clinical picture was strongly suggestive of a partial intermittent intestinal obstruction with a palpable mass in the right iliac fossa. This raised the suspicion of a chronic intussusception or an appendix abscess. Until now the most satisfactory treatment available has been surgical, the operations usually employed being resection of the diseased bowel or by-passing procedures which leave the affected segments in situ (Kirsner and Palmer, 1953). In many cases, however, operative results have been disappointing and recurrences frequent. The problem is that it is often difficult to determine with any degree of accuracy the extent of diseased bowel and how much of the bowel must be resected.

During the last few years several authors have reported some degree of benefit in adult patients by the use of A.C.T.H. and cortisone (Gray, Reifenstein and Benson, 1951; Machella and Hollan, 1951; Kirsner, Palmer and Klotz, 1952). In these patients the disease had been present for years and many had previously been submitted to surgical procedures of one kind or another. Consequently a striking degree of success could hardly be anticipated, but the results were certainly promising, and the pathological lesion appeared to be suppressed. This was the basis that led to a trial of A.C.T.H. in the first case here recorded, as it appeared that in this instance the duration of the disease could be measured in months rather than in years. The boy remained perfectly well and in complete remission for a total of seven months (five months after discontinuing the A.C.T.H.). He then suffered a relapse with abdominal pain, loss of appetite and weight, vomiting and diarrhoea. Oral cortisone was begun in a dose of $37.5 \mathrm{mg}$. b.d. and there has so far been a moderate but distinct improvement, but not the dramatic remission which was witnessed previously. Although there is still radiological evidence of considerable pathological change, some healing appears to be occurring. The ultimate benefit cannot yet be assessed, but in the light of this experience it is suggested that A.C.T.H. is worthy of trial in a child suffering from chronic regional enteritis before surgery is contemplated.

\section{Summary}

Two cases of chronic regional enteritis in children are reported. A.C.T.H. was used in one case and produced a rapid remission.

We wish to thank Professor J. M. Smellie and Dr. Frances Braid for advice and permission to publish these cases, and Mr. J. G. Williamson for the photographs.

\section{REFERENCES}

Bockus, H. L. (1945). J. Amer. med. Ass., 127, 449.

Crohn, B. B. (1949). Regional Ileitis. Grune and Stratton, New York.

Ginzburg, L. and Oppenheimer, G. D. (1932). J. Amer. med. Ass., 99, 1323.

Ebrill, D. (1945). Brit. J. Surg., 32, 512.

Erb, I. H. and Farmer, A. W. (1935). Surg. Gynec. Obstet., 61, 6.

Gray, S. J., Reifenstein, R. W. and Benson, J. A. (1951). New Engl. J. Med., 245, 481 .

Harris, F. I. (1940). Arch. Pediat., 57, 367.

Kirsner, J. B. and Palmer, W. L. (1953). Med. Clin. N. Amer., 37, 237.

Koo, C. and Klotz, A. P. (1952). Gastroenterology, 20, 229. Sci., 214, 27

Machella, T. E. and Hollan, O. R. (1951). Ibid., 221, 501.

Mailer, R. (1938). Brit. J. Surg., 25, 517.

Meade, R. H. (1941). Penn. med. J., 44, 1519.

Oleson, D. (1952). J. Pediat., 40, 671.

Probstein, J. G. and Gruenfeld, G. E. (1936). Ann. Surg., 103, 273.

Shapiro, R., Ravdin, I. S. and Johnston, C. G. (1939). Amer. J. med. Sci., 198, 269.

Storrs, R. C. and Hoekelman, R. A. (1953). New Engl. J. Med., 248,320 . 